\title{
Compensation of flow maldistribution in fin-and-tube evaporators for residential air- conditioning
}

\author{
Kærn, Martin Ryhl; Brix, Wiebke; Elmegaard, Brian; Larsen, Lars Finn Sloth
}

Published in:

International Journal of Refrigeration

Link to article, DOI:

10.1016/j.jirefrig.2011.03.011

Publication date:

2011

Document Version

Early version, also known as pre-print

Link back to DTU Orbit

Citation (APA):

Kærn, M. R., Brix, W., Elmegaard, B., \& Larsen, L. F. S. (2011). Compensation of flow maldistribution in fin-andtube evaporators for residential air-conditioning. International Journal of Refrigeration, 34(5), 1230-1237. https://doi.org/10.1016/j.jirefrig.2011.03.011

\section{General rights}

Copyright and moral rights for the publications made accessible in the public portal are retained by the authors and/or other copyright owners and it is a condition of accessing publications that users recognise and abide by the legal requirements associated with these rights.

- Users may download and print one copy of any publication from the public portal for the purpose of private study or research.

- You may not further distribute the material or use it for any profit-making activity or commercial gain

- You may freely distribute the URL identifying the publication in the public portal 


\title{
Compensation of flow maldistribution in fin-and-tube evaporators for residential air-conditioning
}

\author{
Martin Ryhl Kærn ${ }^{\mathrm{a}, \mathrm{b}, *}$, Wiebke Brix ${ }^{\mathrm{b}}$, Brian Elmegaard ${ }^{\mathrm{b}}$, Lars Finn Sloth Larsen ${ }^{\mathrm{a}}$ \\ ${ }^{a}$ Danfoss A/S, Refrigeration and Air-Conditioning, Nordborgvej 81, DK-6430 Nordborg, Denmark \\ ${ }^{b}$ Department of Mechanical Engineering, Technical University of Denmark, Nils Koppels Allé Bygn. 403, DK-2800 Lyngby, Denmark
}

\begin{abstract}
Compensation of flow maldistribution in multi-channel fin-and-tube evaporators for residential air-conditioning is investigated by numerical modeling. The considered sources of maldistribution are distribution of the liquid and vapor phases in the distributor and non-uniform airflow distribution. Fin-and-tube heat exchangers usually have a predefined circuitry, however, the evaporator model is simplified to have straight tubes, in order to perform a generic investigation. The compensation of flow maldistribution is performed by control of the superheat in the individual channels. Furthermore, the effect of combinations of individual maldistribution sources is investigated for different evaporator sizes and outdoor temperatures. It is shown that a decrease in cooling capacity and coefficient of performance by flow maldistribution can be compensated by the control of individual channel superheat. Alternatively, a larger evaporator may be used.
\end{abstract}

Keywords:

Flow distribution, Compensation, Air-conditioning, Finned tube, Modelling, Simulation

\section{Nomenclature}

\section{Roman}

$F_{x}$ Phase distribution parameter (-)

$F_{\text {air }}$ Airflow distribution parameter (-)

$T_{\text {sh }}$ Superheat temperature (K)

$V$ Velocity $\left(\mathrm{m} \mathrm{s}^{-1}\right)$

$x$ Vapor quality (-)

Subscripts

fr Frontal

in Inlet

$m$ Mean

\section{Introduction}

Flow maldistribution in multi-channel fin-and-tube evaporators has been shown to decrease the performance of air-conditioning systems (Kærn et al., 2011). Maldistribution can be caused by different effects such as non-uniform airflow, non-uniform air temperature, condensation or frost, fouling, an improper heatexchanger, distributor design and installation, or combinations of all these factors.

*Corresponding author. Tel.: +45 4525 4121; fax: +45 45935215. Email address: pmak@mek.dtu.dk (Martin Ryhl Kærn)
Recently, Kærn et al. (2011) conducted a numerical study of flow maldistribution in fin-and-tube evaporators for residential air-conditioning (RAC). It was reported that the non-uniform airflow significantly reduces the cooling capacity and COP, whereas the liquid/vapor phase maldistribution in the distributor does not reach similar impacts on performance. Different feeder tube bending was shown to have a minor effect on the degradation of the cooling capacity and COP. The COP decreased as much as $13 \%$ in the worst case of liquid/vapor phase distribution in the distributor and by $43 \%$ in the worst case of non-uniform airflow distribution, respectively.

Most efforts to compensate for flow maldistribution have addressed the design of the evaporator and, to a less extent, the refrigerant distributor. Domanski and Yashar (2007) applied a novel optimization system called ISHED (intelligent system for heat exchanger design) to optimize refrigerant circuitry in order to compensate for airflow maldistribution. They measured the air velocity profile using particle image velocimetry (PIV) and used that as an input to their numerical model, and found that the cooling capacity increased by $4.2 \%$ compared to an interlaced type of circuitry. Nakayama et al. (2000) and Li et al. (2005) studied dif- 
ferent distributors and compensation for refrigerant flow maldistribution by changing the design of the distributor. Nakayama et al. (2000) reported that their novel distributor, which had a capillary mixing space, achieved the best refrigerant distribution. Li et al. (2005) reported that, in general, a spherical base distributor achieved the best refrigerant distribution, and that the orifice should be located closest to the distributor base.

Studies regarding the benefits of controlling individual superheat have also been conducted. Choi et al. (2003) conducted an experimental study on a fin-andtube evaporator and found that a non-uniform airflow could be recovered to within $2 \%$ of the original cooling capacity under uniform airflow conditions, while keeping the air flow rate constant. The individual channel pressure drops were adjusted by needle valves to achieve the same individual channel superheat. Kim et al. (2009a,b) studied the benefits of upstream vs. downstream control of individual channel superheat on a fin-and-tube five channel R410A heat pump. Two and three of the channels, respectively, were treated similarly. Essentially, there were two circuits, where one had $50 \%$ larger area than the other. Their method involved fine-tuning the miniature valves located upstream or downstream of the evaporator along with an overall thermostatic expansion valve. Essentially, the method controlled the individual superheats by adjusting the pressure drop through the channels. The study showed that the upstream control outperformed the downstream control. They also found that the capacity reduction due to maldistribution could be recovered up to $99.9 \%$ by using upstream control. Using downstream control resulted in minor benefits due to the increased pressure drop at the exit of the evaporator.

Flow maldistribution can be compensated for by using an expansion valve for each channel. Another option is to increase the size of the evaporator. The first option is unfeasible due to the costs associated with installing additional expansion valves. The second option may have restrictions on the size of the air ducts. For economical reasons, any type of refrigerant distribution control must be less expensive than the costs of increasing the size of the evaporator in order to deliver the same cooling capacity.

To compensate for maldistribution, a new method was evaluated in the current study with respect to cooling capacity and the coefficient of performance (COP). This method involved a coupled expansion and distributor device that was able to control the individual channel superheat by measuring only the overall superheat (Funder-Kristensen et al., 2009; Mader and Thybo, 2010).
In a previous study considering the effects of flow maldistribution, Kærn et al. (2011) developed a model of an $8.8 \mathrm{~kW}$ R410A RAC system. The model was capable of simulating refrigerant and airflow maldistribution in fin-and-tube evaporators as well as the effects of maldistribution on cooling capacity and the coefficient of performance (COP). The model was verified under uniform flow conditions with the commercial software Coil-Designer (Jiang et al., 2006). The same model was used in the current study to exploit the benefits of compensating for flow maldistribution. The evaporator was an A-coil and consisted of two coils each with two channels. In order to perform a generic investigation, each evaporator coil model was simplified to be two straight channels where each channel was aligned in the first row and meet the same inlet air temperature. Furthermore, each coil was assumed to have similar flow distribution conditions.

The objective of the current study was to perform a generic investigation of the benefits of compensating for flow maldistribution by controlling individual superheats. As a baseline for comparison, an analysis of flow maldistribution was carried out where different combinations of maldistribution sources were considered with different evaporator sizes and outdoor temperatures. In particular, inlet liquid/vapor phase distribution and airflow distribution in the evaporator were considered. The new method of compensation was then compared to the baseline results of combined flow maldistribution.

This paper includes a brief description of the modeling framework, an analysis of the new method for compensation and a comparison of the method against the combined maldistribution with different evaporator sizes and outdoor temperatures.

\section{The simulation model}

A detailed formulation of the numerical model that was used in the current study was previously described in Kærn et al. (2011). A brief description is given here.

The system model focused on the evaporator in order to predict the maldistribution in the evaporator and its effect on system performance. Lumped parameter, quasi-static model formulations were used for the expansion device and the compressor. The evaporator model was a distributed one-dimensional mixture model, and the condenser model was a simpler moving boundary model (Zhang and Zhang, 2006) that averaged the liquid, two-phase and vapor regions. Pressure drop was only considered in the evaporator and its feeder tubes to predict the mass flow distribution. Both the evaporator and condenser models were dynamic, and 
Table 1: Main geometry of the evaporator and condenser

\begin{tabular}{lcc}
\hline & Evaporator & Condenser \\
\hline Number of coils & 2 & 1 \\
Number of channels in each coil & 2 & 5 \\
Number of tubes in each channel & 18 & 6 \\
Tube length [mm] & 444.5 & 2100 \\
Inner tube diameter [mm] & 7.6 & 7.6 \\
Outer tube diameter [mm] & 9.6 & 9.6 \\
Fins & Louvred & Louvred \\
Fin pitch [mm] & 1.81 & 1.15 \\
Total outside area $\left[\mathrm{m}^{2}\right]$ & 19.2 & 52.2 \\
Number of cells & 30 & \\
\hline
\end{tabular}

thus they modeled the refrigerant migration between the evaporator and the condenser. The model was implemented in Dymola 7.1 (2008).

\subsection{Geometry and correlations}

Table 1 shows the main geometry of the test case evaporator and condenser. The feeder tubes to the evaporator had an internal diameter of $3 \mathrm{~mm}$ and a length of $300 \mathrm{~mm}$.

Figure 1 shows a sketch of the model setup including a zoomed-in sketch of the evaporator, which only shows one of the two evaporator coils. Each discrete cell of the evaporator was calculated as a small heat exchanger with uniform transport properties. Mass, momentum and energy conservation equations were applied to the refrigerant in each cell, where homogeneous flow and thermodynamic equilibrium was assumed. Furthermore, changes in kinetic and potential energy were neglected. The tube walls were assumed to have rotational symmetry. Mass and energy conservation equations were applied to the air, which was assumed to be dry.

Similar assumptions were used in the condenser model of the refrigerant and airflow. However, the heat transfer resistance and the dynamics in the condenser wall were neglected. The correlations for both the evaporator and the condenser are given in table 2. Furthermore, appropriate effectiveness-NTU relations for cross flow heat exchangers were used.

The expansion was modeled as an isenthalpic process. The manifold was modeled by mixing the refrigerant streams, where the mass and energy conservation equations were applied.

The geometric volume flow of the compressor was $6.239 \mathrm{~m}^{3} \mathrm{~h}^{-1}$. Polynomials from the rating of the compressor were used to compute the isentropic and volumetric efficiencies.
Table 2: Overview of used correlations

\begin{tabular}{|c|c|}
\hline \multicolumn{2}{|l|}{ Air-side } \\
\hline Heat transfer & Wang et al. (1999) \\
\hline Fin efficiency & Schmidt (1949) \\
\hline & (Schmidt approximation) \\
\hline \multicolumn{2}{|l|}{ Single phase } \\
\hline Heat transfer & Gnielinski (1976) \\
\hline Friction & Blasius (2002) \\
\hline \multicolumn{2}{|c|}{ Two-phase (evaporator) } \\
\hline Heat transfer & Shah (1982) \\
\hline Friction & Müller-Steinhagen and Heck (1986) \\
\hline \multicolumn{2}{|c|}{ Two-phase (condenser) } \\
\hline Heat transfer & Shah (1979) \\
\hline
\end{tabular}

\subsection{Distribution parameters}

In order to study different inlet liquid/vapor phase distributions and non-uniform airflow distributions to the evaporator, we have defined two distribution parameters. The symbols used in the following are shown in figure 1. Note that the zoomed-in sketch only shows one of the two evaporator coils.

The phase distribution parameter was defined by

$$
F_{x}=\frac{x_{2}}{x_{\text {in }}} \quad 0 \leq F_{x} \leq 1
$$

When $F_{x}$ is unity, the vapor quality into the feeder tubes is equal. When $F_{x}$ is zero, only liquid is fed into channel 2. Mass and energy conservation equations were applied to compute the vapor quality in channel 1 .

The airflow distribution parameter was defined by

$$
F_{\text {air }}=\frac{V_{\mathrm{fr}, 2}}{V_{m}} \quad 0 \leq F_{\text {air }} \leq 2
$$

where $V_{m}$ is the mean frontal velocity across the two tubes. When $F_{\text {air }}$ is unity, the airflow is distributed equally across the two tubes. When $F_{\text {air }}$ is zero, the air flow across channel 1 only. When $F_{\text {air }}$ is two, the air flow across channel 2 only. The mass flow rate of air across the evaporator was held constant, and the mass conservation equation was used to compute the frontal velocity of channel 1 .

\subsection{Boundary conditions}

The system used an electrostatic expansion valve (EXV) that controlled the overall superheat to $5 \mathrm{~K}$. When compensating for flow maldistribution, the expansion device controlled each channel superheat to 5 $\mathrm{K}$ by means of the individual mass flow rates. During the start-up of the simulation with no maldistribution, the charge of the system was determined so that 


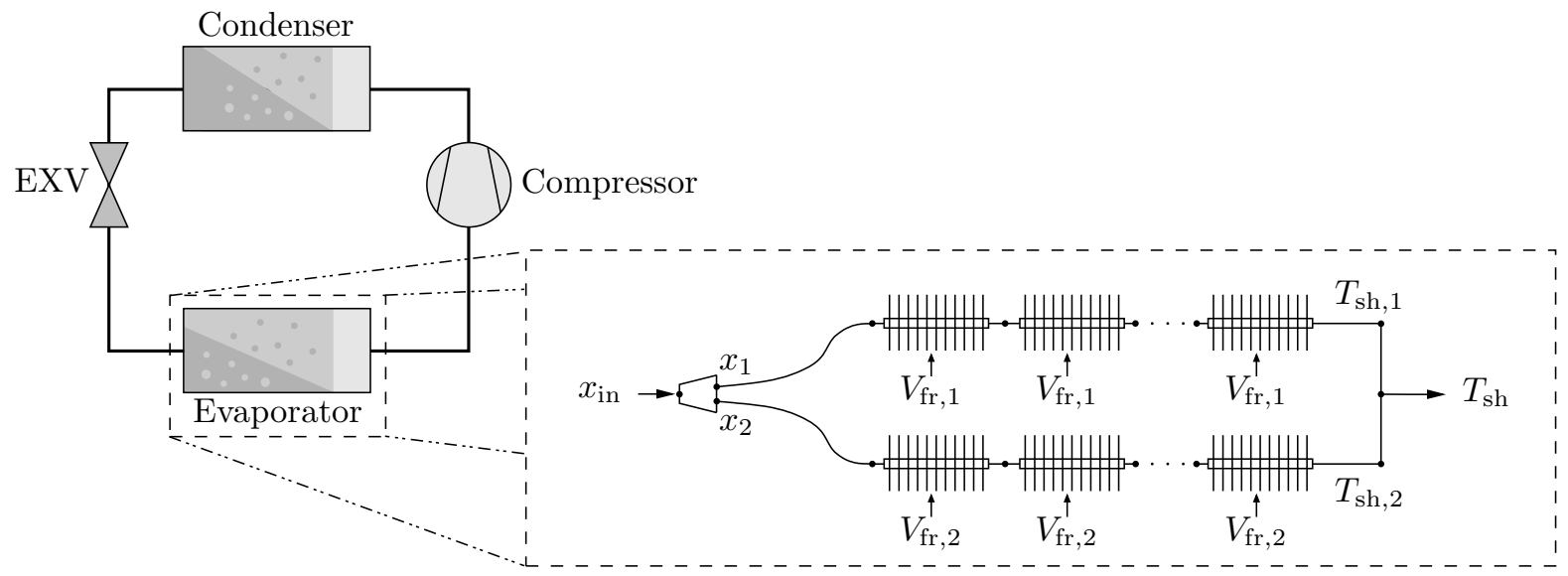

Figure 1: Sketch of the model setup

the subcooling became $2 \mathrm{~K}$. Then the different distribution parameters were varied, and each steady state result was obtained. Unless specified otherwise, the indoor and outdoor air temperatures were $26.7^{\circ} \mathrm{C}$ and $35^{\circ} \mathrm{C}$, respectively. The mean frontal air velocities are 1.16 and $0.68 \mathrm{~m} \mathrm{~s}^{-1}$ to the evaporator and condenser, respectively. The required fan power was not addressed in this study and thus not included in the definition of COP. However, we found that the required fan power in order to move air through the coils was less than $1 \%$ of the compressor power by computing the air-side pressure drop through the coils using Coil-Designer at uniform conditions. Furthermore, the required power for the expansion device was assumed negligible.

\subsection{Flow maldistribution}

The presented system model was used in Kærn et al. (2011) to simulate the individual effects of flow maldistribution in fin-and-tube evaporators. The studied sources of flow maldistribution were a non-uniform airflow distribution, non-uniform liquid/vapor inlet distribution and different feeder tube bending. The main conclusions were that the non-uniform airflow significantly reduces the cooling capacity and COP, whereas the liquid/vapor phase maldistribution in the distributor does not reach similar impacts on performance. Different feeder tube bending was shown to have a minor effect on the degradation of the cooling capacity and COP. In the following section, we continue the investigation of flow maldistribution by studying the combined flow maldistribution that may occur as well as compensation for flow maldistribution. More information on individual flow maldistribution is given in Kærn et al. (2011).

\section{Compensation of flow maldistribution}

The method of compensation involved a coupled expansion and distributor device, which was able to distribute the mass flow according to the individual superheat of each channel. The distribution occurred before the expansion, and the actual expansion occurred into the individual feeder tubes. Moreover, the inlet specific enthalpy to each channel was the same, and the expansion device compensated for the liquid/vapor maldistribution by design. Thus, in this section we only varied the airflow distribution parameter.

By allowing the individual mass flows to be controlled for the case with compensation, the pressure drop through each channel was not necessarily equal, as was the case without compensation. Therefore, an additional inlet pressure difference was allowed in the model for the case with compensation.

Figure $2 \mathrm{a}$ shows the comparison of the refrigerant mass flow rates as function of the airflow distribution parameter either with compensation or without compensation.

The result showed how the mass flows should be distributed as function of the airflow distribution parameter to achieve equal superheat out of the channels. The total mass flow through the coil could thus be held high, indicating a higher cooling capacity during compensation. The channel that received less airflow also received less refrigerant flow and vice versa. Without compensation, the individual mass flow curves were similar. However, both curves decreased as airflow maldistribution increased, indicating a lower cooling capacity. The individual mass flows were computed according to the pressure drop through each channel, which was set to be equal for the case without compensation. Despite the 
(a)

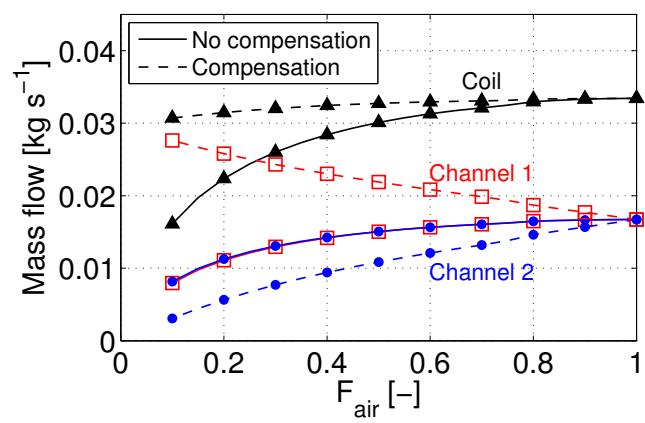

(b)

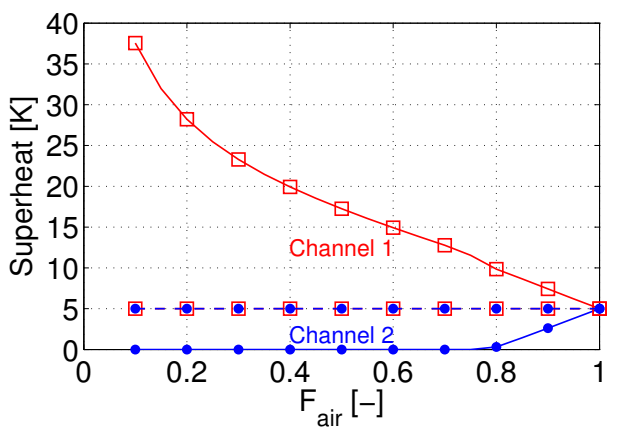

(c)

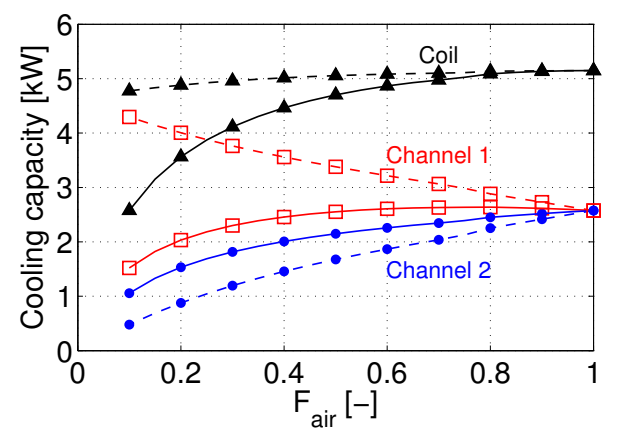

(d)

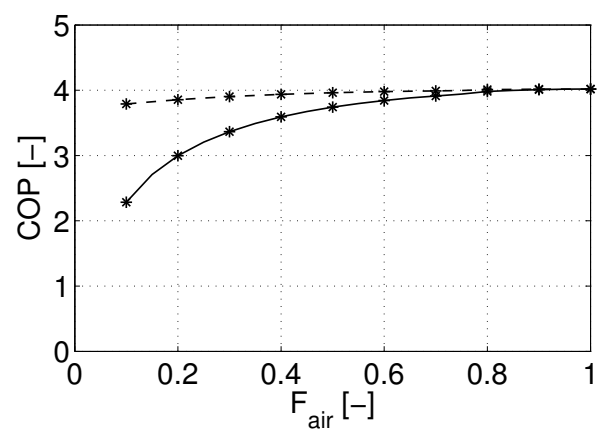

Figure 2: Selected parameters vs. the airflow distribution parameter; Solid lines $=$ no compensation of maldistribution, dashed lines $=$ compensation by control of individual superheat.

different superheated areas in each channel, the mass flows became the same. Similar results were found in Kim et al. (2009a) for airflow maldistribution.
The control of the individual channel superheat eliminated the different superheated regions, as shown in figure $2 \mathrm{~b}$. The control eliminated the decrease in the overall UA-value as liquid started to come out of channel 2 $\left(F_{\text {air }}=0.8\right)$ when there was no compensation. A higher superheated region with a lower UA-value was required in channel 1 to evaporate this surplus liquid. In turn, the lower UA-value resulted in a lower mass flow rate to ensure that the overall superheat of $5 \mathrm{~K}$ was maintained when there was no compensation.

The result of the recovered overall UA-value and mass flow rate with compensation was a recovery of the cooling capacity and COP, as indicated in figure $2 \mathrm{c}$ and $2 \mathrm{~d}$. With compensation, the degradation in total cooling capacity was only $7.2 \%$ compared to $49.9 \%$ at $F_{\text {air }}=0.1$. The degradation in COP was only $5.7 \%$ with compensation compared to $43.2 \%$ at $F_{\text {air }}=0.1$.

\section{Combination of flow maldistribution and com- pensation}

To fully evaluate the benefits of the new compensation method, we also needed to address the inlet liquid/vapor phase distribution in the comparison as well as the possibility that the two sources of flow maldistribution might act together or compensate for each other. For these reasons, we varied both the airflow distribution parameter $F_{\text {air }}$ from 0.5 to 1.5 as well as the phase distribution parameter $F_{x}$ from 1 to 0.2 in this section.

The individual effect on the cooling capacity as $F_{\text {air }}$ changed from 0.5 to 1.5 and $F_{x}$ changed from 1 to 0.2 is shown in figure 3 . The figure also shows the results of the compensation method from section 3 .

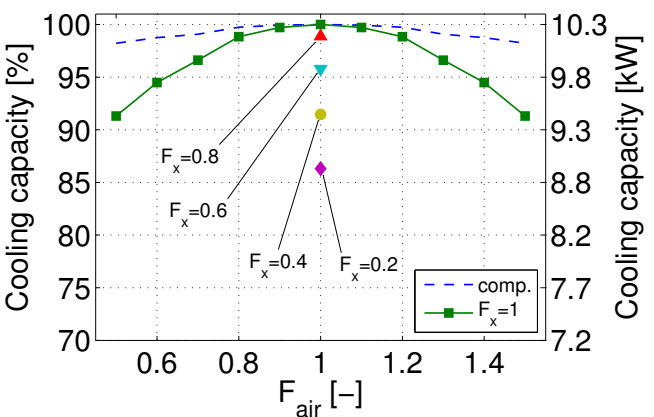

Figure 3: Evaporator capacity vs. individual maldistribution source.

The cooling capacity decreased by $13.7 \%$ as $F_{x}$ went to 0.2 . A more thorough study of liquid/vapor maldistribution in the distributor was performed by Kærn et al. (2011). Basically, the differences in the liquid and vapor pressure drop in each channel altered the distribution of 
mass flow and, as a result, individual channel superheat. This alteration decreased the cooling capacity and COP. When $F_{\text {air }}$ and $F_{x}$ was unity at uniform flow conditions, the cooling capacities reached maximum value.

The combined maldistribution condition was studied by varying both $F_{\text {air }}$ and $F_{x}$ simultaneously. Figure $4 \mathrm{a}$ and $4 \mathrm{~b}$ show the cooling capacity and the COP of the system. The graphs show both the actual values and the relative performance compared to the maximum.

The figures show that the individual maldistribution sources may act together or cancel each other out. The sources acted together when $F_{x}<1$ and $F_{\text {air }}<1$. When $F_{x}<1$, a higher superheated area was present in channel 1 because channel 2 received more liquid. Simultaneously, the airflow across channel 1 increased for $F_{\text {air }}<1$ so that an even higher superheated area in channel 1 occurred (see figure 4c). When $F_{x}<1$ and $F_{\text {air }}>1$, the maldistribution sources compensated for each other. The airflow maldistribution was compensated for by the inlet liquid/vapor distribution, which resulted in a higher cooling capacity and COP as the values for $F_{x}<1$ become higher than the values for $F_{x}=1$ (upper right corner of the graphs).

The maximum of each curve was similar to the condition where the individual channel superheats were controlled, which indicate a maximum performance. Figure $4 \mathrm{c}$ shows the individual channel superheats in each coil. We found it interesting that the maximum performance at combined flow maldistribution was not obtained when the individual superheats were equal. The curve $F_{x}=0.8$ revealed a maximum performance at $F_{\text {air }}=1.2$. However, the individual superheats were equal at $F_{\text {air }}=1.24$. Furthermore, the curve $F_{x}=0.6$ showed a maximum performance at $F_{\text {air }}=1.4$, whereas the individual superheats were equal at $F_{\text {air }}=1.48$.

The maximum performance for combined flow maldistribution might occur when the two-phase area in the evaporator is at its highest value, because the two-phase area has a higher heat transfer than the single phase area. Figure $4 \mathrm{~d}$ shows the percentage of the two-phase area in the evaporator. The values were discrete values because the evaporator model was discretized in the flow direction. We observed that the two-phase area could neither be used as a measure for maximum performance at combined flow maldistribution. For instance, the curve $F_{x}=0.6$ showed that the highest two-phase area was greater or equal to $F_{\text {air }}=1.5$. However, the maximum performance was at $F_{\text {air }}=1.4$.

\subsection{Different evaporator sizes}

The penalties of airflow and inlet liquid/vapor maldistribution were compensated for by controlling individ- (a)

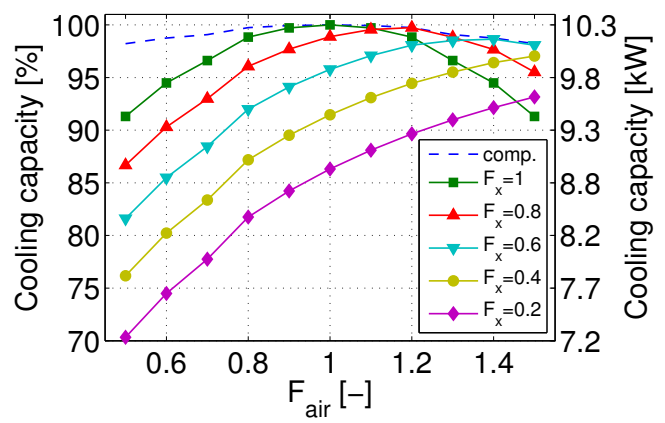

(b)

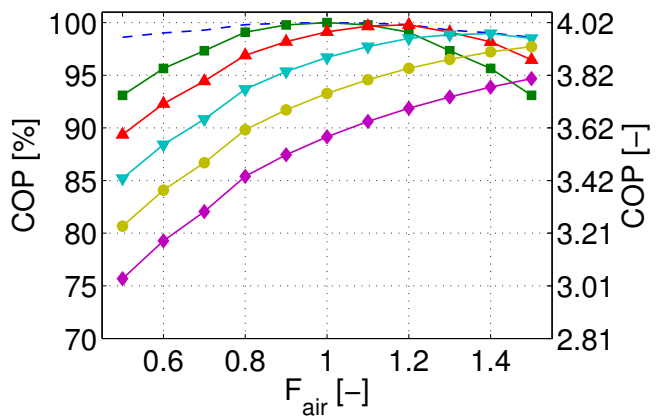

(c)

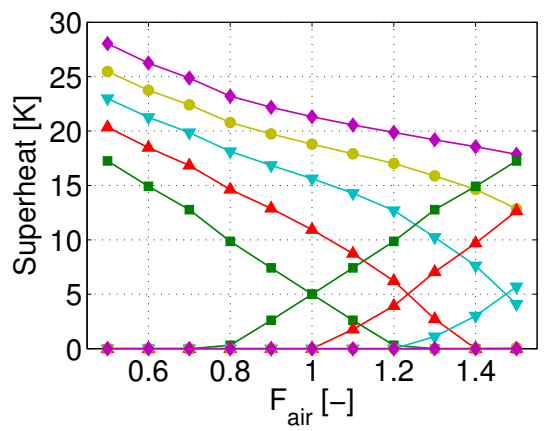

(d)

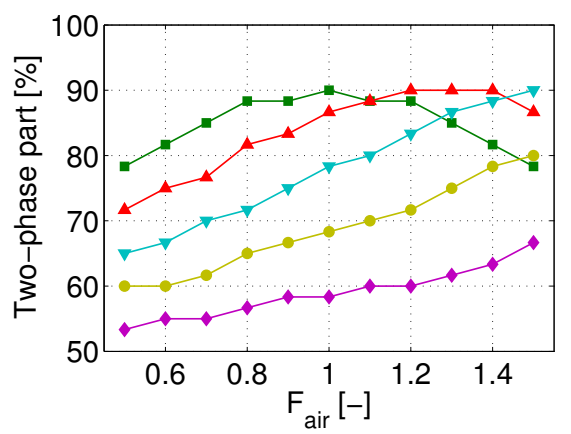

Figure 4: Combined maldistribution of inlet liquid/vapor and airflow (8.8 kW evaporator, outdoor temperature $\left.=35^{\circ} \mathrm{C}\right)$. Evaporator capacity (a), COP (b), individual superheat (c) and two-phase part (d).

ual superheats. A common alternative to increasing the COP is to increase the area of the evaporator.

Figure $5 \mathrm{a}$ and $5 \mathrm{~b}$ show the combined effects of flow 
maldistribution for the same system, but with a larger evaporator $(10.5 \mathrm{~kW})$, i.e. a larger indoor unit. The evaporator basically had the same coil geometry, but there were two extra tubes in each channel and a higher mean frontal air velocity of $1.25 \mathrm{~m} \mathrm{~s}^{-1}$.

(a)

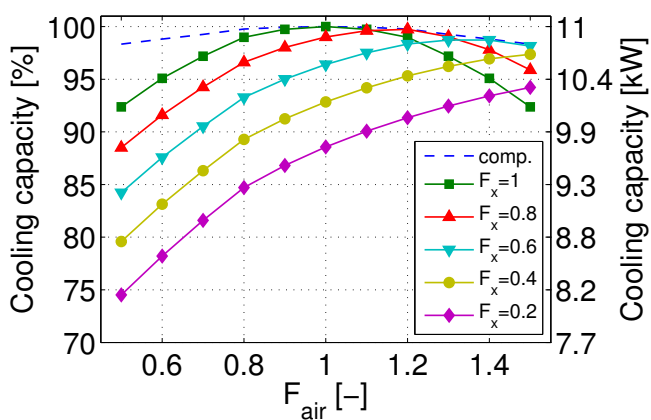

(b)

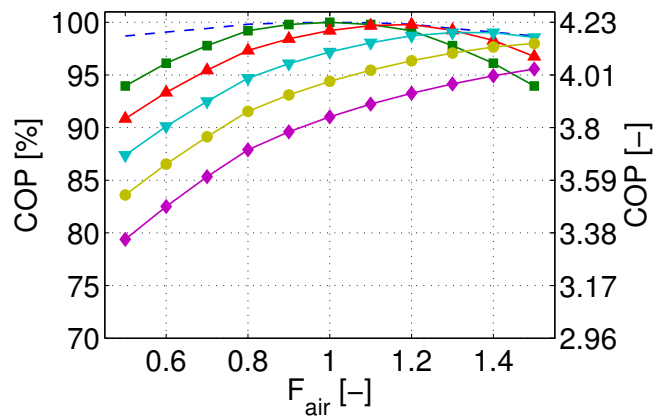

Figure 5: Combined maldistribution of inlet liquid/vapor and airflow $\left(10.5 \mathrm{~kW}\right.$ evaporator, outdoor temperature $\left.=35^{\circ} \mathrm{C}\right)$. Evaporator capacity (a) and COP (b)

Note that increasing the evaporator size from 8.8 to $10.5 \mathrm{~kW}$ did not provide $1.7 \mathrm{~kW}$ of extra cooling capacity if the compressor and condenser were not upgraded similarly, but COP improved.

When using a larger evaporator, the \%-degradations were a little smaller, which indicated that larger sizes of the evaporator could cause less degradation. Thus, high performance systems with large evaporators would not necessarily have benefits that are similar to the benefits of using a smaller performance system. However, there should be an incentive to minimize the size of the evaporator by using the new method of compensation.

In the following, an analysis of the results is described. If maldistribution occurred at $F_{\text {air }}=0.7$ and $F_{x}=0.8$, the COP of the $8.8 \mathrm{~kW}$ unit became 3.80 (figure $4 b$ ). If we used the larger evaporator (figure $5 b$ ), the COP at a similar maldistribution became 4.04 , which corresponded to an increase of $6.3 \%$. If we instead controlled individual superheats in the $8.8 \mathrm{~kW}$ unit, the COP was 3.99 (figure 4b), which corresponded to an in- crease of $5.0 \%$, which is comparable. The cost of the compensation device must then be less than the difference in cost between the two evaporators.

A similar analysis may be conducted for other maldistribution conditions. For example, at $F_{\text {air }}=0.9$ and $F_{x}=0.6$, the increase in COP was $6.0 \%$ using the larger evaporator and $5.0 \%$ using the compensation device.

\subsection{Different outdoor temperatures}

Figure $6 \mathrm{a}$ and $6 \mathrm{~b}$ show the effects of combined maldistribution for the $8.8 \mathrm{~kW}$ evaporator at an outdoor temperature of $27.8^{\circ} \mathrm{C}$.

(a)

(b)
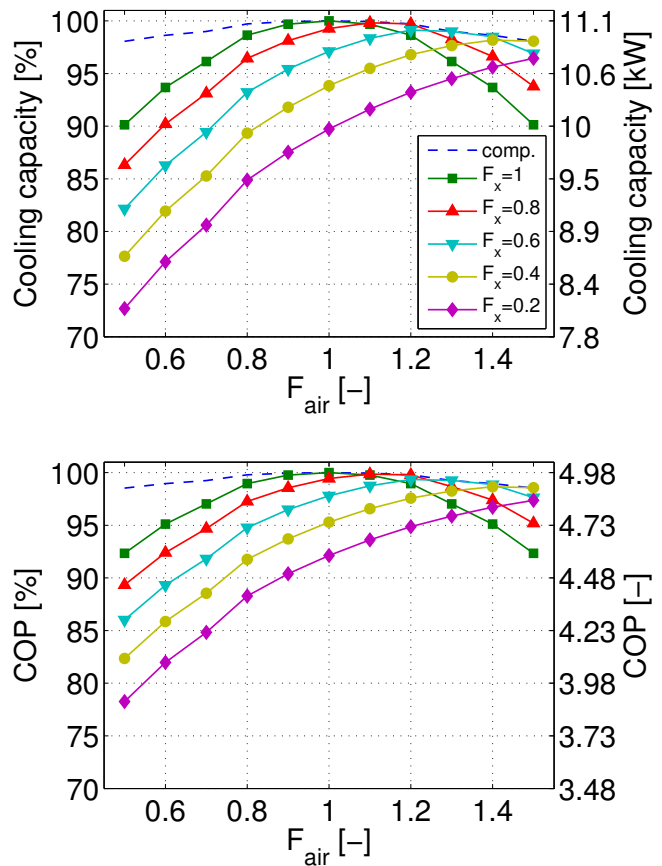

Figure 6: Combined maldistribution of inlet liquid/vapor and airflow $\left(8.8 \mathrm{~kW}\right.$ evaporator, outdoor temperature $\left.=27.8^{\circ} \mathrm{C}\right)$. Evaporator capacity (a) and COP (b)

The reduction in cooling capacity and COP showed similar trends for lower outdoor temperatures. Since the temperature difference between the indoor condition and the outdoor condition was smaller, the COP of the system was higher. As the outdoor temperature decreased, the inlet quality to the evaporator also decreased. As a result, the potential for the inlet liquid/vapor maldistribution was lower. This trend can be seen in the curves when $F_{x}<1$, which showed less reduction compared to figure 4 . 


\section{Discussion}

The results of this paper may be used as guidelines for predicting the possible degradation or recovery in cooling capacity and COP at flow maldistribution in the evaporator, whenever it is caused by the distributor or the airflow. The readers need to be cautioned that it is not practical to have evaporator coils consisting of two straight tubes. For investigating practical airflow maldistribution in A-coils, we need to account for actual circuitry, since the maldistribution has varied impacts on different circuitry patterns. However, if we accounted for a particular circuitry we would lose the generality in our model.

Furthermore, it may be difficult to estimate the velocity profile for a given type of A-coil, since it depends on many factors such as apex angle, mounting brackets, condensate pans, upstream and downstream flow obstructions, bends or blower locations in the duct system. For example in studies by Yashar et al. (2008) and AbdelAziz et al. (2008), the velocity field showed a recirculation zone with low air velocities inside the coils located farthest away from the apex. In a later study by Yashar and Domanski (2010) on another A-coil, no recirculation zone was found. Furthermore, these investigations were made at uniform and undisturbed upstream airflow, which may not be the case at installation of these systems.

The reader may use our results by making a qualitative guess on the degree of flow maldistribution $\left(F_{\text {air }}\right.$ and $F_{x}$ ) considering the actual tube circuiting and airflow arrangement.

In this study, we assumed that the two coils in the evaporator worked under similar maldistribution conditions. However, there could be maldistribution between the coils themselves. Maldistribution may also be worse when the system is in part-load operation or operated under off-design conditions. Furthermore, dehumidifying conditions may cause larger airflow maldistribution as was shown experimentally by Yashar and Domanski (2010).

Kim et al. (2009b) also performed a system level analysis of flow maldistribution in evaporators. They found that the cooling capacity and COP could be recovered to $99.9 \%$ at $F_{\text {air }}=0.71$ by controlling individual superheat. The results of this study showed a cooling capacity recovery of $99.1 \%$ and a COP recovery of $99.3 \%$ at $F_{\text {air }}=0.71$. There was a good correspondence between the results of the two findings.

\section{Conclusion}

The studied method to compensate for flow maldistribution in evaporators for residential air-conditioning significantly recovered the airflow maldistribution in terms of cooling capacity and COP. The method involved the control of individual channel superheat by distributing individual channel mass flow rates accordingly. The distribution of the liquid and vapor phases occurred before the expansion so that the liquid and vapor phase distribution was uniform into the feeder tubes and thus compensated by design.

To fully evaluate the benefits of the new compensation method, we studied the different combinations of maldistribution sources that have been shown to be significant for performance (Kærn et al., 2011), without using the compensation method. This included the liquid and vapor phase distribution in the distributor and the airflow distribution. It was found that the different combinations either outbalanced and compensated for each other or increased the reduction in cooling capacity and COP. When the sources outbalance the results showed a maximum recovery similar to the new compensation method.

Furthermore, the effects of different evaporator sizes and outdoor temperatures were studied at combined flow maldistribution. We found nearly the same \%degradations for these cases.

The results of this paper showed that when using the new compensation method, the COP of the $8.8 \mathrm{~kW}$ R410A unit increased by $5.0 \%$ at a flow maldistribution of $F_{\text {air }}=0.7$ and $F_{x}=0.8$ or $F_{\text {air }}=0.9$ and $F_{x}=0.6$. When upgrading the evaporator from $8.8 \mathrm{~kW}$ to 10.5 $\mathrm{kW}$, the COP increased by $6.3 \%$ and $6.0 \%$, respectively.

\section{References}

AbdelAziz, O., Singh, V., Aute, V., Radermacher, R., 2008. A-type heat exchanger simulation using 2-d CFD for airside heat transfer and pressure drop. In: 12th International Refrigeration and AirConditioning Conference at Purdue. No. 2200. West Lafayette, IN, USA.

Blasius, P. R. H., 2002. VDI Wärmeatlas, 9th Edition. Springer-Verlag Berlin Heidelberg New York.

Choi, J. M., Payne, W. V., Domanski, P. A., 2003. Effects of nonuniform refrigerant and air flow distributions on finned-tube evaporator performance. In: 21th International Congress of Refrigeration. IIR/IIF, Washington, D.C.

Domanski, P. A., Yashar, D., 2007. Application of an evolution program for refrigerant circuitry optimization. In: ACRECONF "Challenges To Sustainability". New Delhi, India.

Dymola 7.1, 2008. Dynamic Modeling Laboratory, Dymola User's Manual, version 7.1. Dynasim AB, Research Park Ideon SE-223 70, Lund, Sweden. 
Funder-Kristensen, T., Nicolaisen, H., Holst, J., Rasmussen, M. H., Nissen, J. H., 2009. Refrigeration system. US Patent, Pub. No.: US 2009/0217687 A1.

Gnielinski, V., 1976. New equation for heat and mass transfer in turbulent pipe and channel flow. International Chemical Engineering 16, 359-368.

Jiang, H., Aute, V., Radermacher, R., 2006. Coildesigner: A generalpurpose simulation and design tool for air to refrigerant heat exchangers. International Journal of Refrigeration 29, 601-610.

Kim, J.-H., Braun, J. E., Groll, E. A., 2009a. Evaluation of a hybrid method for refrigerant flow balancing in multi-circuit evaporators. International Journal of Refrigeration 32, 1283-1292.

Kim, J.-H., Braun, J. E., Groll, E. A., 2009b. A hybrid method for refrigerant flow balancing in multi-circuit evaporators: Upstream versus downstream flow control. International Journal of Refrigeration 32, 1271-1282.

Kærn, M. R., Brix, W., Elmegaard, B., Larsen, L. F. S., 2011. Performance of residential air-conditioning systems with flow maldistribution in fin-and-tube evaporators. International Journal of Refrigeration 34 (3), 696 - 706.

Li, G., Frankel, S., Braun, J. E., Groll, E. A., 2005. Application of CFD models to two-phase flow in refrigeration distributors HVAC\&R Research 11 (1), 45-62.

Mader, G., Thybo, C., 2010. An electronic expansion valve with automatic refrigerant distribution control. In: Deutsche Kälte-KlimaTagung. Magdeburg, Germany.

Müller-Steinhagen, H., Heck, K., 1986. A simple friction pressure drop correlation for two-phase flow in pipes. Chemical engineering and processing 20, 297-308.

Nakayama, M., Sumida, Y., Hirakuni, S., Mochizuki, A., 2000. Development of a refrigerant two-phase flow distributor for a room air conditioner. In: 8th International Refrigeration Conference at Purdue. West Lafayette, IN, USA, pp. 313-319.

Schmidt, T. E., 1949. Heat transfer calculations for extended surfaces. Refrigerating Engineering, 351-357.

Shah, M. M., 1979. A general correlation for heat transfer during film condensation inside pipes. International Journal of Heat and Mass Transfer 22, 547-556.

Shah, M. M., 1982. Chart correlation for saturated boiling heat transfer: Equations and further study. ASHRAE Transactions 88, 185 196

Wang, C.-C., Lee, C.-J., Chang, C.-T., Lin, S.-P., 1999. Heat transfer and friction correlation for compact louvered fin-and-tube heat exchangers. International Journal of Heat and Mass Transfer 42, 1945-1956.

Yashar, D. A., Cho, H. H., Domanski, P. A., 2008. Measurement of air-velocity profiles for finned tube heat exchangers using particle image velocimetry. In: 12th International Refrigeration and AirConditioning Conference at Purdue. No. 2195. West Lafayette, IN, USA.

Yashar, D. A., Domanski, P. A., 2010. Air flow distribution through an a-shaped evaporator under dry and wet coil conditions. In: 13th International Refrigeration and Air-Conditioning Conference at Purdue. No. 2100. West Lafayette, IN, USA.

Zhang, W.-J., Zhang, C.-L., 2006. A generalized moving-boundary model for transient simulation of dry-expansion evaporators under larger disturbances. International Journal of Refrigeration 29, 1119-1127. 